\title{
Neurological complications and death in children with dengue virus infection: report of two cases
}

\author{
Neydi Osnaya-Romero 1,2, Maria-Gabriela Perez-Guille1, Sandra Andrade-García², Erika Gonzalez-Vargas², \\ Rebeca Borgaro-Payro², Sandra Villagomez-Martinez', José de Jesús Ortega-Maldonado² \\ and Jose Luis Arredondo-García ${ }^{1 *}$
}

\begin{abstract}
Background: Dengue virus infection can have different complications; the best known is hemorrhagic dengue fever. However, other effects such as neurological disorders may endanger the lives of patients. Dengue neurological manifestations can be confused with encephalitis symptoms and can lead to cerebral edema and death. Therefore, we consider important in the endemic areas to take into account the diagnosis of dengue encephalitis in patients with neurological disorders, and to request the determination of serology in cerebrospinal fluid for the NS1 antigen test.

Case presentation: We present the cases of two patients from the state of Morelos, Mexico, with 17 and 14 years of age. Both cases presented a rapid evolution characterized by fever, seizures and neurological deterioration secondary to severe cerebral edema that evolved to cerebral death in both cases. The diagnosis of brain death was confirmed by electroencephalogram in both patients. The two patients were submitted to serology for NS1 that tested positive in both cases. They died between the second and fifth day after admission.

Conclusions: Retrospective studies have found that up to $4 \%$ of the patients have dengue virus infections, which leads us to believe that in endemic areas, this infection should be suspected in cases of encephalic and febrile symptoms. RT-PCR should be performed to identify cases of encephalitis caused by the dengue virus, and early interventions should be performed to attempt to reduce the morbidity and mortality of these cases.
\end{abstract}

Keywords: Dengue, Dengue virus, Neurological disorders, Death, Children

\section{Background}

The WHO defines dengue as a mosquito-borne viral disease, whose global incidence has grown dramatically in recent decades. It is estimated that about half of the world's population is now at risk. Dengue virus is transmitted by female mosquitoes, mainly Aedes aegypti and to a lesser extent by $A$. albopictus. These mosquitoes also transmit chikungunya fever, yellow fever, and Zika virus infection. Dengue is widespread in the tropics, with local variations in risk that are largely dependent on rainfall, temperature, and unplanned rapid urbanization.

\footnotetext{
* Correspondence: arredondo.joseluis@gmail.com

${ }^{1}$ Intituto Nacional de Pediatria Insurgentes Sur 3700, letra C, Col. Insurgentes Cuicuilco, CP 04530 Ciudad de México, Mexico

Full list of author information is available at the end of the article
}

Severe dengue (previously known as dengue hemorrhagic fever) affects most Asian and Latin American countries and has become one of the leading causes of hospitalization and death in children and adults in those regions [1].

Dengue virus fever can have deadly consequences. There are records of this disease since the Jin Dynasty (265-420 AD), and the first epidemics were reported in 1780. It was originally defined as "break-bone fever" due to the symptoms commonly observed in those afflicted.

Dengue virus (DENV) belongs to the family Flaviviridae and is an RNA virus composed of three structural protein genes, which encode the nucleocapsid or core (C) protein, a membrane-associated $(\mathrm{M})$ protein, an enveloped (E) glycoprotein and seven non-structural 
(NS) proteins. Four serotypes have been described to date: DV-1, DV-2, DV-3, and DV-4 [2].

After being bitten by $A$. aegypti carrying the virus, individuals are infectious during the first five days of viremia. When an infected individual is bitten again by a mosquito, that mosquito will ingest infected blood; a blood meal involving another person thereby perpetuates the cycle. Isolating the virus requires serum collection during the first five days after symptoms appear [3].

All four serotypes have been identified in 29 states of Mexico, with a peak number of cases in 2007 and 2009. However, differences in records of suspected cases are caused by overreporting in endemic areas and underreporting in non-endemic areas. IgM antibodies, which are only present in $80 \%$ of patients during the febrile stage and can persist for three months, must be detected for diagnosis verification. In contrast, identification of IgG antibodies indicates a secondary infection. Polymerase chain reaction (PCR) detection of the NS1 antigen during the first five days of fever can indicate viral replication or an infection when other tests are negative.

Cytokine production facilitates capillary permeability, favoring fluid extravasation and mononuclear infiltration into muscles along with increases in creatine phosphokinase, producing myalgia. Treatment includes controlling fever and pain by physical means or with paracetamol [4].

DENV infection can have different clinical presentations, the most classic of which is a difficult-to-control fever accompanied by myalgia, arthralgia headache, retroocular pain, rash, and abdominal pain. Severe cases can present with epistaxis, petechiae, gastrointestinal (GI) bleeding, ascites, pleural effusion, heart attack, hypotension, tachycardia, alterations in state of consciousness, fulminant hepatitis, myocardiopathy, and encephalitis. Severe dengue can also cause shock and death [3]. In addition, there are reports that approximately $20 \%$ of cases of severe dengue develop vital organ involvement and complications [5].

Severe liver disorders are the most frequent complication, as diagnosed by significant alterations in liver function and other signs such as metabolic encephalopathy, jaundice, and alithiasic cholecystitis [6]. Cardiac conditions present with supraventricular bradycardia or tachycardia, T-wave inversion, and cardiac dysfunction [7]. Moreover, acute renal failure has been reported, associated with high mortality rates in $3 \%$ of dengue patients with shock [8]. Other complications involve aplastic anemia, rash, severe thrombocytopenia, pulmonary complications, cholecystitis, hemophagocytic syndrome, pancreatitis, and acute abdomen [9-11].

It is estimated that approximately $10 \%$ of dengue patients present with neurological disorders during or after infection, suggesting that the virus may induce neurological dysfunction, either directly by invading and infecting nervous tissue or indirectly via other organs that affect nervous function. These neurological complications include encephalitis/encephalopathy, meningitis, myelitis, cerebellitis, and acute disseminated encephalomyelitis. Up to $4 \%$ of dengue patients may develop neuromuscular complications such as myalgia, myositis, rhabdomyolysis and hypokalemic paralysis. Neurological complications frequently accompany severe dengue infection [12, 13].

Such potential neurological complications reaffirm the need to include neurological manifestations as a criterion of infection severity, as suggested by the WHO since 2009 , because these manifestations can result in significant sequelae and even death $[14,15]$.

Here, we describe a case of two sisters in Axochiapan, Morelos, Mexico (a dengue endemic/epidemic region), who presented with fever and seizures caused by dengue and unfortunately died as a result of the infection.

Axochiapan is located in sanitary jurisdiction number 3 of the state of Morelos, geographically located at $18^{\circ}$ $30^{\prime \prime}$ north latitude and $98^{\circ} 45^{\prime \prime}$ west longitude of the Greenwich meridian, at a mean height of 1030 meters asl, with a surface area of $1423.10 \mathrm{~km}^{2}$. The 2010 census reported a population of 33,695 , of which $60.3 \%$ are poor ( $48.7 \%$ moderate poverty and $11.6 \%$ extreme poverty); $31.9 \%$ of the people do not have access to health services, and $19.6 \%$ of the population live in poor-quality housing, do not have basic services, and lack access to adequate food [16, 17].

According to a WHO and PAHO report released in August 2016, there are 643,577 confirmed cases of dengue globally. In Mexico, 26,665 cases were reported with a lethality of 2.49; the serotypes identified include DN-1, $-2,-3$, and -4. As of September 2015, Morelos Health Services had recorded 335 cases of dengue throughout the state, of which 34 cases occurred in the municipality of Axochiapan. In 2016, 515 cases were reported in the state of Morelos, of which 30 correspond to the municipality of Axochiapan, with a rate of 81.86 and including serotypes DV-1, -2 , and $-3[18,19]$.

\section{Case Presentation}

\section{Case 1}

The patient, a 17-year-old female, was admitted to the hospital on June 4, 2016, at 2:50 am. She had a history of seizures at eight years of age. She was managed with diphenylhydantoin for two years, after which the medication was discontinued. Her current illness began after returning from a school trip. At the end of the day, her teachers observed generalized tonic-clonic movements with increased muscle tone, though the duration was not noted. She was transferred to the regional hospital in Xochitepec, Morelos, where diphenylhydantoin was administered. However, her seizures continued. Epileptic 
status was suspected, and the decision was made to protect the airways with orotracheal intubation. She was then moved to Children's Hospital of Morelos. On admission, she did not exhibit respiratory effort, corneal reflex, or cough reflex. ACT revealed cerebral edema and severe ventricular collapse (Fig. 1).

Her laboratory and blood tests reported are presented in Table 1. The patient remained on respiratory support. Two electroencephalograms (EEGs) were performed, with both being isoelectric. Based on the clinical and EEG reports, brain death was determined, and the patient was declared dead two days after admission. Reported serology for dengue NS1 via enzyme-linked immunoassay (ELISA) was positive; PCR to detect enterovirus in the cerebrospinal fluid (CSF) was negative.

\section{Case 2}

A 14-year-old female was admitted to the hospital on June 5, 2016, at 2:20 am. The patient's symptoms started $12 \mathrm{~h}$ after clinical manifestation in her sister (Case 1). She had a $39{ }^{\circ} \mathrm{C}$ fever and headache progression for $24 \mathrm{~h}$. She presented with psychomotor agitation, followed by generalized tonic-clonic seizures. She was taken to Axochiapan Morelos Hospital for assessment. On admission, she exhibited neurological deterioration requiring orotracheal intubation and was sent to Children's Hospital of Morelos, where cranial computerized axial tomography (CAT) revealed severe cerebral edema and uncal herniation (Fig. 2). Her laboratory blood tests are presented in Table 1. She was transferred to the intensive care unit where hemodynamic and antiedema care was provided. On beginning intensive care, clinical data indicated brain death, which was confirmed by three isoelectric EEGs. The patient died in the hospital five days after admission. Serology positive for dengue NS1 by ELISA was reported, and PCR was performed to detect enterovirus in the CSF, with negative results.

Both patients underwent anti-doping and immunoglobulin testing on admission (Table 1). At the time of interview, family members responsible for both patients were asked about any background that might indicate probable toxic poisoning of the patients, but no positive indications were obtained. When questioned about whether there was another member of the family with the same clinical picture, the mother of the children said that on June 3 of the same year, her 6-year-old daughter had a fever of $38{ }^{\circ} \mathrm{C}$. She was taken to a health center in the community of Axochiapan Morelos where paracetamol was prescribed, which improved the symptoms, and no other complications presented. Due to the history of the complications suffered by the patients, serology for dengue NS1 in the 6-year-old child was performed by ELISA, with a positive result.

In our country, the ELISA and PCR tests used for the detection of dengue virus are based on the
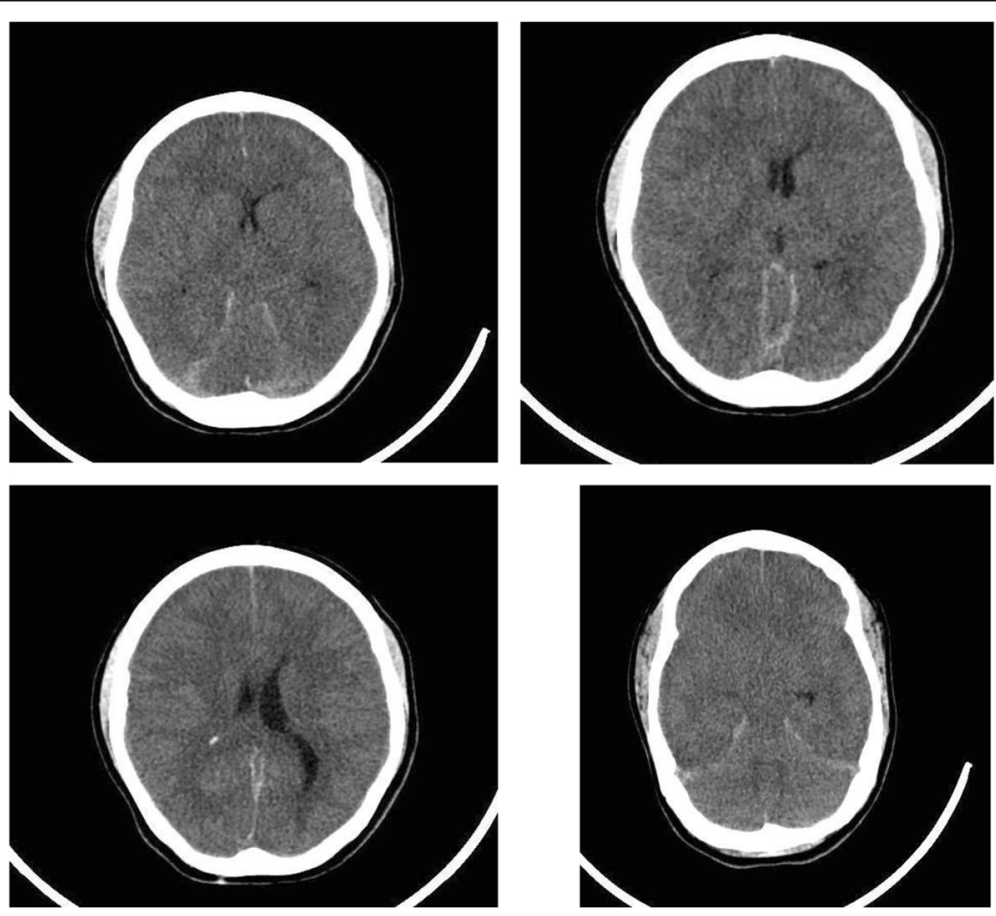

Fig. 1 Computerized axial tomography of the brain with diagnosis of global cerebral edema, showing effacement of the subarachnoid cisterns and compression of the cerebral sulcus and gyrus and of the right ventricular system 
Table 1 Laboratory tests reported in the patients studied

\begin{tabular}{|c|c|c|}
\hline Parameter & $\begin{array}{l}\text { Case } 1 \\
\text { (17 years) }\end{array}$ & $\begin{array}{l}\text { Case } 2 \\
\text { (14 years) }\end{array}$ \\
\hline Weight (kg) & 52 & 45 \\
\hline Glucose mg/dL & 109 & 148 \\
\hline Serum sodium meq/L & 141 & 156 \\
\hline Serum potassium meq/L & 2.2 & 3.29 \\
\hline Serum calcium mg/dL & 6.9 & 6.8 \\
\hline Serum creatinine mg/dL & 0.6 & 0.7 \\
\hline Total bilirubin mg/dL & 0.28 & 0.30 \\
\hline Direct bilirubin mg/dL & 0.10 & 0.11 \\
\hline Indirect bilirubin mg/dL & 0.16 & 0.19 \\
\hline Glutamic pyruvic transaminase U/L & 33 & 25 \\
\hline Glutamic oxaloacetic transaminase U/L & 23 & 17 \\
\hline Alkaline phosphatase U/L & 64 & 88 \\
\hline Phosphorus mg/dL & & 3.21 \\
\hline Prothrombin time sec. & 15.9 & 15.7 \\
\hline Thromboplastin time sec. & 26.5 & 24.2 \\
\hline INR & 74.21 & 1.33 \\
\hline Hemoglobin g/dL & 12 & 10.6 \\
\hline Hematocrit \% & 34.1 & 32.3 \\
\hline Platelets $\times 10^{3} / \mathrm{mm}^{3}$ & 152 & 143 \\
\hline Leucocytes mm $\mathrm{m}^{3}$ & 4.54 & 5.93 \\
\hline Segmented \% & 85 & 94 \\
\hline Bands \% & & 4 \\
\hline Monocytes \% & 2 & 1 \\
\hline Lymphocytes \% & 13 & 5 \\
\hline Fibrinogen mg/dL & & 272 \\
\hline \multicolumn{3}{|l|}{ CSF } \\
\hline Proteins (mg/dL) & 1629.8 & 84.2 \\
\hline Glucose mg/dL & 1 & 87 \\
\hline Chloride $\mathrm{mEq} / \mathrm{L}$ & 134 & 122 \\
\hline Leucocytes $\mathrm{mm}^{3}$ & 0 & 0 \\
\hline Gram stain & Negative & Negative \\
\hline CSF culture & Negative & Negative \\
\hline Ant doping & Negative & Negative \\
\hline $\lg A(m g / d L)$ & 148 & 150 \\
\hline $\operatorname{lgG}(\mathrm{mg} / \mathrm{dL})$ & 750 & 867 \\
\hline $\operatorname{lgM}(\mathrm{mg} / \mathrm{dL})$ & 117 & 123 \\
\hline Immunoglobulin E (UI/mL) & 87.1 & 327 \\
\hline
\end{tabular}

Epidemiological Diagnostic and Reference guidelines of the Department of Health [20], performed as follows.

\section{Platelia NS1 ELISA}

A commercial kit (Platelia NS1) that is an immunoenzymatic method useful for qualitative or semiquantitative detection of the dengue virus NS1 antigen in human serum or plasma was used. The assay utilizes murine monoclonal antibodies (mAbs) for antigen capture and detection. Samples from patients and controls are incubated directly and simultaneously with the diluted conjugate for $90 \mathrm{~min}$ at $37{ }^{\circ} \mathrm{C}$. Any NS1 antigen present in the sample will form an immune complexes, mAb-NS1$\mathrm{mAb} /$ peroxidase, which is detected using the enzymatic development solution, promoting a colored reaction (blue). After $30 \mathrm{~min}$ of incubation at room temperature, the enzymatic reaction is stopped by the addition of an acid solution (stop solution). The optical density obtained at $450 / 620 \mathrm{~nm}$ is proportional to the amount of NS1 antigen present in the sample. The presence of the antigen in a sample is established by comparing the optical density of this sample with that obtained in threshold serum. The results are interpreted according to the following criteria:

- Nonreactive: A sample with an index value $<0.5$ is considered non-reactive for the dengue virus NS1 antigen.

- Equivocal: A sample with an index value between 0.5 and 1.0 is considered equivocal for the dengue virus NS1 antigen; such a sample should be analyzed again.

- Reactive: A sample with an index value $>1.0$ is considered reactive for the dengue virus NS1 antigen.

\section{Detection and identification of dengue virus serotypes by multiplex real-time RT-PCR}

Multiplex real-time reverse transcriptase-PCR (RT-PCR) has the ability to monitor the progress of amplification in each cycle. Data are collected from the first reaction cycle to the last, allowing relative and absolute quantification of the viral load present in the sample. Amplification of a specific sequence is monitored by detection of fluorescence signals emitted during the PCR cycles. The presence of high concentrations of RNA or number of copies of genetic material will cause an early increase in fluorescence, whereas low concentrations of RNA will cause an increase in fluorescence in later reaction cycles. As the dengue virus circulates in detectable concentrations during the acute phase of the disease (0-5 days), this assay is only used during the acute phase and in samples positive for the NS1 antigen. The results are interpreted according to the following criteria:

- Negative: There is no viral RNA present, or there is an extremely low viral load related to the sensitivity of the method.

- Positive: "Dengue virus infection is only indicated by NS1 positivity." 


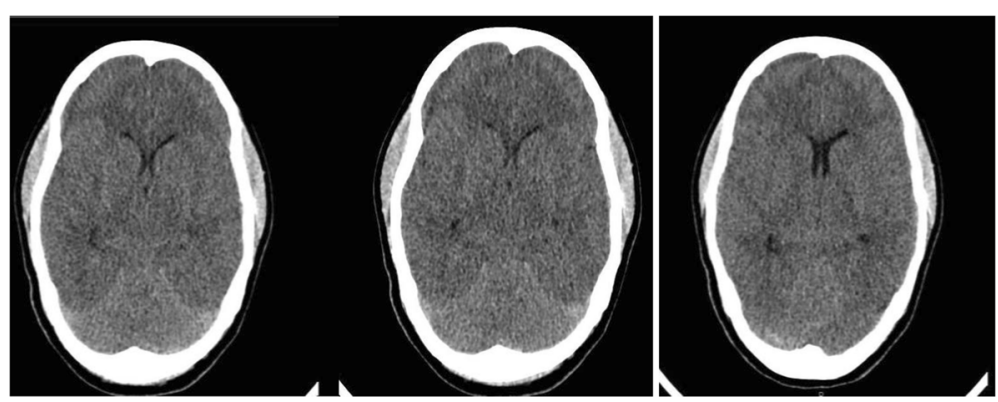

Fig. 2 Computerized axial tomography with diffuse cerebral edema, showing loss of differentiation between grey and white matter and compression of the ventricles

A positive result is indicative of recent infection and the presence of viral RNA of the serotype(s) detected. Multiplex real-time RT-PCR determines the presence of RNA from the four dengue virus serotypes in serum and plasma. A positive result is indicative of recent infection caused by the serotype(s) identified.

\section{Discussion}

Both patients had seizures and alterations in the state of consciousness. Toxic poisoning was ruled out by the clinical history and a negative anti-doping test. None of the $\mathrm{CBC}$ results pointed to a bacterial process. CSF was analyzed by gram-staining to assess the presence of bacteria and by RT-PCR to detect the presence of enterovirus, with negative results in both cases. Proteins, which may be present or not in cases of encephalitis, were found in the CSF in only one patient [21]. Therefore, the most likely diagnosis to be considered was encephalitis, probably caused by dengue virus infection based on the endemic area where the patients lived; this is why a determination by ELISA was requested. Having obtained a positive dengue virus NS1 antigen ELISA, with a sensitivity of $80-100 \%$ and a specificity of $94-100 \%$, and a negative enterovirus PCR, with a sensitivity of $100 \%$ and a specificity of $77 \%$, the diagnosis of neuro-dengue was confirmed in both patients [20]. The clinical manifestations presented by these patients coincide with those reported by Carod-Artal et al. [12], who concluded that the diagnosis of neuro-dengue can be established in patients with fever and neurological manifestations in dengue endemic regions.

Neurological manifestations in patients with DENV infection are not common. Indeed, some authors have reported such manifestations in only 5.4 to $10 \%$ of patients with severe dengue. These manifestations of the central nervous system appear as headache, vomiting, and neck rigidity. Only when performing specific serology for dengue can this neurological complication be identified; otherwise, cases are diagnosed as encephalitis or meningitis $[12,13]$. Cases of dengue fever with neurological manifestations have a higher risk of death, as reported in studies in Brazil, with a mortality rate of $1.9 \%$ $[22,23]$. When dealing with a febrile clinical picture, a systemic inflammatory response should be ruled out, as should other leptospirosis pathologies, malaria, infectious hepatitis, yellow fever, meningococcemia, rubella, and influenza [23]. It is not yet clear how damage is caused in such neurological alterations in dengue virus infection; the effect may be due to the virus infecting nerve cells or as a result of the disruption of other organs, such as the liver [14]. There are three ways in which neurological alterations occur in DENV infection: non-specific encephalopathy, specific encephalopathy, and post-infection encephalitis. Other explanations of neurological disorders include liver disease, cerebral edema, and hyponatremia, without discarding the possibility of direct damage by the virus to the central nervous system $[24,25]$.

Research on the etiopathology of neurological manifestations in dengue is diverse. For example, it was initially thought that neurological manifestations were due to anti-dengue antibodies [26, 27]. Later research reported that encephalitis occurs as a consequence of direct invasion of DENV into the brain, as viral antigens have been detected in the inferior olivary nucleus of the medulla oblongata and in the granular layer of the cerebellum [14].

In patients with suspected dengue virus infection and neurological manifestations, it is vital to document these alterations by means of imaging studies such as magnetic resonance imaging (MRI). However, given that this technique is not readily available in many health centers, a brain CAT scan could be used instead; if the patient dies, autopsy would provide more information about the alterations caused by this infection.

In the patients reported herein, electrolytes and liver function tests did not show alterations that could explain the neurological manifestations. A limitation of this study was that the only imaging technique available 
was a brain CAT scan, based on which the presence of severe cerebral edema was established. EEGs were also obtained, with total absence of EEG activity suggesting brain death. Unfortunately, autopsy could not be performed in these cases.

\section{Conclusion}

To date, the physiopathology of neurological manifestations in DENV infection, as well as its incidence, are unknown. In some cases, patients are admitted with a diagnosis of encephalitis. Furthermore, retrospective studies have found that up to $4 \%$ of these patients have DENV infections, which leads us to believe that in endemic areas, dengue virus infection should be suspected in cases of encephalic and febrile symptoms. RT-PCR should be performed to identify cases of encephalitis caused by the dengue virus, and early interventions should be performed to attempt to reduce the morbidity and mortality of these cases.

\section{Abbreviations \\ CAT: Computerized axial tomography; CSF: Cerebrospinal fluid; \\ CSF: Cerebrospinal fluid; DENV: Dengue virus; EEG: Electroencephalogram; ELISA: Enzyme-linked immunoassay; GI: Gastrointestinal; MRI: Magnetic resonance imaging; PCR: Polymerase chain reaction; RT-PCR: Reverse transcriptase polymerase chain reaction}

\section{Acknowledgments}

We thank the health services of the state of Morelos and the authorities of the Hospital del Niño Morelense for providing access to their facilities in order to carry out this study.

\section{Funding}

Not applicable.

\section{Authors' contributions}

NOR, SAG, EGV, and JJOM made substantial contributions to the conception and design of the study and to the acquisition of data. MGPG and RBP made substantial contributions to the conception and design of the study and to the analysis and interpretation of the data. NOR, MGPG, SVM, and JLAG were involved in drafting the manuscript and revising it critically for important intellectual content. SVM and JLAG are denque experts and made substantial contributions to the conception and design of the study. All of the authors read and approved the final manuscript, agreed to be accountable for all aspects of the work, and ensure that questions related to the accuracy or integrity of any part of the work are appropriately investigated and resolved.

\section{Competing interests}

The authors declare that they have no competing interests.

\section{Consent for publication}

Written informed consent was obtained from the parents of the patients for publication of this case report.

\section{Ethics approval and consent to participate} Not applicable.

\section{Publisher's Note}

Springer Nature remains neutral with regard to jurisdictional claims in published maps and institutional affiliations.

\section{Author details}

'Intituto Nacional de Pediatria Insurgentes Sur 3700, letra C, Col. Insurgentes Cuicuilco, CP 04530 Ciudad de México, Mexico. ${ }^{2}$ Morelense Children's Hospital, Emiliano Zapata, Morelos, Mexico.
Received: 14 December 2016 Accepted: 8 April 2017

Published online: 27 April 2017

\section{References}

1. World Health Organization. Weekly epidemiological record. Dengue and severe dengue. http://www.who.int/mediacentre/factsheets/fs117/en/. Accessed 29 Jul 2016.

2. Gupta N, Srivastava S, Jain A, Chaturvedi UC. Dengue in India. Indian J Med Res. 2012:136(3):373-90.

3. Acosta-Bas C, Gómez-Cordero I. Biología y métodos diagnósticos del denque. Rev Biomed. 2005;16(2):113-37.

4. Fajardo-Dolci G, Meljem-Moctezuma J, Vicente-González E, Venegas-Páez FV, Mazón-González B, Aguirre-Gas HG. The dengue fever in Mexico. Knowledge for improving the quality in health]. Rev Med Inst Mex Seguro Soc. 2012;50(6): 631-9 [Article in Spanish].

5. Lee MS, Hwang KP, Chen TC, Lu PL, Chen TP. Clinical characteristics of dengue and dengue hemorrhagic fever in a medical center of southern Taiwan during the 2002 epidemic. J Microbiol Immunol Infect. 2006;39(2): $121-9$.

6. Pancharoen C, Rungsarannont A, Thisyakorn U. Hepatic dysfunction in dengue patients with various severity. J Med Assoc Thai. 2002;85 Suppl 1: S298-301

7. Salgado DM, Panqueba CA, Castro D, R Vega M, Rodríguez JA. [Myocarditis in children affected by dengue hemorrhagic fever in a teaching hospital in Colombia]. Rev Salud Publica (Bogota). 2009;11(4):591-600 [Article in Spanish].

8. Wiwanitkit V. Acute renal failure in the fatal cases of dengue hemorrhagic fever, a summary in Thai death cases. Ren Fail. 2005;27(5):647. doi:10.1080/ 08860220500200916

9. Ramzan M, PrakashYadav S, Sachdeva A. Post-dengue fever severe aplastic anemia: a rare association. Hematol Oncol Stem Cell Ther. 2012;5(2):122-4. doi:10.5144/1658-3876.2012.122.

10. Mena Lora AJ, Fernandez J, Morales A, Soto Y, Feris-Iglesias J, Brito MO. Disease severity and mortality caused by dengue in a Dominican pediatric population. Am J Trop Med Hyg. 2014;90(1):169-72. doi:10.4269/ajtmh.13-0440.

11. Méndez A, González G. [Abnormal clinical manifestations of dengue hemorrhagic fever in children]. Biomedica. 2006;26(1):61-70 [Article in Spanish].

12. Carod-Artal FJ, Wichmann O, Farrar J, Gascón J. Neurological complications of dengue virus infection. Lancet Neurol. 2013;12(9):906-19. doi:10.1016/ S1474-4422(13)70150-9.

13. Garg RK, Malhotra HS, Jain A, Malhotra KP. Dengue-associated neuromuscular complications. Neurol India. 2015;63(4):497-516. doi:10.4103/ 0028-3886.161990.

14. Castellanos J, Bello J, Velandia-Romero M. Manifestaciones neurológicas durante la infección por el virus del dengue. Infectio. 2014;18(4):167-76. doi:10.1016/j.infect.2014.02.006.

15. Palma-da Cunha-Matta A, Soares-Moreno SA, Cardoso-de Almeida A, Aquilera-de Freitas V, Carod-Artal FJ. [Neurological complications arising from dengue virus infection]. Rev Neurol. 2004;39(3):233-7 [Article in Spanish].

16. Dirección General de Epidemiología. Secretaria de Salud, Mexico. https:// www.gob.mx/cms/uploads/attachment/file/211212/Pano_dengue_sem_14_ 2017.pdf.

17. Catálogo de claves de entidades federativas, municipios y localidades México. Instituto Nacional de estadística y geografía. www.gob.mx/cms/ uploads/attachment/file/45715/Morelos_003.pdf. Accessed 24 May 2011.

18. Servicios de Salud de Morelos. Aguas con el Dengue. www.gob.mx/cms/ uploads/attachment/file/120810/Pano_dengue_sem_30_2016.pdf.

19. Pan American Health Organization. Number of reported cases of dengue and Severe dengue (SD) in the Americas, By country. http://www2.paho. org/hq/index.php?option=com_docman\&task=doc_download\&ltemid= 270\&gid $=37782 \&$ lang $=$ es.

20. Instituto de Diagnóstico y Referencia Epidemiológicos, Salud. Lineamientos para la Vigilancia por laboratorio de Dengue. Version 2.0. InDRE:RNLSP; 2012. http://web.ssaver.gob.mx/uies/files/2015/03/03LINEAMIENTOS_DENGUE_InDRE-RNLSP.pdf.

21. Navarro Gómez ML, González F, Santos Sebastián M, Saavedra Lozano J Hernández Sampelayo Matos T. Sección de enfermedades infecciosas pediátricas. Hospital General Universitario Gregorio Marañón. Madrid. http://www.aeped.es/sites/default/files/documentos/encefalitis.pdf. 
22. Araújo F, Nogueira R, Araújo M de S, Perdigão A, Cavalcanti L, Brilhante R, et al. Dengue in patients with central nervous system manifestations, Brazil. Emerg Infect Dis. 2012;18(4):677-9. doi:10.3201/eid1804.111552.

23. Querales J. Dengue: causas, características clínicas y prevención. Gac Med Caracas. 2002;110(3):322-32.

24. Jackson ST, Chu JJH, Chia PY, Morgan OSC, Ng LC. Denque encephalitis. In: Růžek D, editor. Flavivirus encephalitis. Rijekak: Intech; 2011. p. 25-52.

25. Sudhir U, Anil Kumar T, Gupta B, Punith K. Dengue menigoencephalitis. J Indian Acad Clin Med. 2010;11(2):141-3.

26. Brito-Ferreira ML, Cavalcanti CG, Alvarenga Coelho C, Mesquita SD. Manifestações neurológicas de dengue. Estudo de 41 casos. Arq Neuropsiquiatr. 2005;63(2-B):488-93

27. Wasay M, Channa R, Jumani M, Shabbir G, Azeemuddin M, Zafar A. Encephalitis and myelitis associated with dengue viral infection clinical and neuroimaging features. Clin Neurol Neurosurg. 2008;110(6):635-40. doi:10.1016/j.clineuro.2008.03.011.

Submit your next manuscript to BioMed Central and we will help you at every step:

- We accept pre-submission inquiries

- Our selector tool helps you to find the most relevant journal

- We provide round the clock customer support

- Convenient online submission

- Thorough peer review

- Inclusion in PubMed and all major indexing services

- Maximum visibility for your research

Submit your manuscript at www.biomedcentral.com/submit
Biomed Central 